\title{
Neurosonology and Imaging in Uncommon Causes of Stroke
}

\author{
Seung Min Kim*, Sang Hee $\mathrm{Ha}^{\dagger}$, Sang Mi Noh${ }^{\ddagger}$, Sung Hyuk $\mathrm{Heo}^{\dagger}$, Bum Joon $\mathrm{Kim}^{\dagger}$ \\ Department of Neurology, VHS Medical Center*, Seoul; Department of Neurology, Kyung Hee University Hospital ${ }^{\dagger}$, Seoul; Department of \\ Neurology, The Catholic University of Korea St. Vincent Hospital ${ }^{\ddagger}$, Suwon, Korea
}

Most ischemic strokes are caused by large artery atherosclerosis, small vessel occlusive disease, or cardioembolism. However, there are some uncommon causes of stroke as well, especially in young stroke patients. These uncommon causes of stroke require various and complex diagnostic work-ups. However, some of them have characteristic neuroimaging or neurosonologic findings, making the diagnosis much easier. Since finding the exact cause of stroke is very important in determining the therapeutic strategy and predicting the prognosis, clinicians should become familiar with these imaging and sonologic characteristics of uncommon causes of stroke. Recently, many novel imaging techniques have been introduced, but neurosonology is still a simple, widely available, noninvasive, and useful technique. This review will discuss the clinical, neurosonologic, and neuroimaging features of uncommon causes of stroke (cervical artery dissection, Takayasu arteritis, patent foramen ovale-stroke, Moyamoya disease, and sickle cell disease) and review current diagnostic methods.

J Neurosonol Neuroimag 2019;11(1):34-45

Key Words: Uncommon cause stroke; Ultrasonography, Doppler; Neuroimaging
Received: May 3, 2019

Revised: June 6, 2019

Accepted: June 11, 2019

Address for correspondence: Bum Joon Kim

Department of Neurology, Kyung Hee University Hospital, 23 Kyungheedae-ro, Dongdaemun-gu, Seoul o2447, Korea Tel: +82-2-958-8499 Fax: $+82-2-958-5491$ E-mail: medicj8o@hanmail. net

\section{INTRODUCTION}

Stroke is a heterogeneous disease that may be caused by various mechanisms, and defining the mechanism of stroke is the first step in making treatment decisions. The majority of ischemic strokes are caused by large artery atherosclerosis, small vessel occlusive disease, or cardioembolism. However, one-in-ten ischemic strokes are caused by so-called uncommon causes of stroke.

Uncommon causes of stroke include dissection, vasculitis, Moyamoya disease (MMD), stroke associated with patent foramen ovale (PFO; PFO-stroke), sickle cell disease (SCD), or coagulopathies caused by various conditions such as anti-phospholipid antibody syndrome or thrombotic thrombocytopenic purpura. Most of the causes are classified as "other determined stroke" in the TOAST classification, except PFO-stroke. The treatment and prognosis of these strokes also depend on the etiology. Therefore, diagnosing the exact cause of stroke may be important. In particular, when the direct cause of stroke is uncommon, the patient's history and imaging findings are crucial. Furthermore, neuroimaging, including sonolgy, is important in the diagnosis of uncommon causes of stroke.

Neurosonological evaluation has several advantages in showing the following: real-time hemodynamic status; direct imaging of the vessel wall, where the pathologic processes take place; and special sonologic features that may help identify conditions which can cause stroke. Vasculitis or MMD usually causes stroke by a hemodynamic mechanism after the diffuse narrowing of extracranial or intracranial vessels. Dissection or vasculitis occurring in extracranial arteries can be visualized easily by carotid duplex sonography. Agitated saline testing may help find right-to-left shunting.

Here, we review the imaging and neurosonological findings of uncommon causes of stroke (summarized in Table 1) and describe how these studies can be used to 
TABLE 1. Summary of imaging findings of uncommon cause stroke

\begin{tabular}{|c|c|c|}
\hline & nal imaging & Neurolsonology \\
\hline $\begin{array}{l}\text { Cervical artery } \\
\text { dissection }\end{array}$ & $\begin{array}{l}\text { Intimal flaps or double lumen } \\
\text { Dissecting aneurysm } \\
\text { Intramural hematoma (crescentic hyperdensity with thickening } \\
\text { of the vessel wall on CT, hyperintense area beside the vessel } \\
\text { lumen on MRI) } \\
\text { MRI } \\
\text { Decrease or absence of signal void with crescent sign } \\
\text { DSA } \\
\text { String sign (long segment of narrowed lumen) } \\
\text { HR-MRI } \\
\text { Eccentric wall thickening and vessel wall enhancement }\end{array}$ & $\begin{array}{l}\text { Intimal flap or mural hematoma as a thickened } \\
\text { hypoechoic wall } \\
\text { Stenosis or occlusion without atherosclerotic } \\
\text { wall change } \\
\text { Righ-resistance pattern in Doppler spectra } \\
\text { TCD } \\
\text { Reversed ophthalmic artery flow or other intra- } \\
\text { cranial collaterals } \\
\text { Microembolic signal }\end{array}$ \\
\hline Tak & $\begin{array}{l}\text { MRI } \\
\text { Acute stage } \\
\text { Wall thickening and enhancement around an inflamed vessel } \\
\text { Chronic stage } \\
\text { Segmental dilatation with stenotic regions of the common } \\
\text { carotid and subclavian artery } \\
\text { Advanced-stage disease } \\
\text { Complete occlusion of supra aortic arteries at their origin, } \\
\text { with multiple bypass collateral vessels }\end{array}$ & $\begin{array}{l}\text { Macaroni sign } \\
\text { Homogeneous, isoechoic, concentric wall } \\
\text { thickening } \\
\text { Inflammation-driven hyperemia and neovascu- } \\
\text { larization on contrast-enhanced ultrasound } \\
\text { TCD } \\
\text { "Pulseless" cerebral vascular spectra ipsilateral } \\
\text { to the extracranial lesion } \\
\text { Subclavian steal syndrome }\end{array}$ \\
\hline PFO-stroke & $\begin{array}{l}\text { Small ischemic lesion usually located at the cortex in posterior } \\
\text { circulation }\end{array}$ & Micro embolic signals in agitated saline test \\
\hline Moyamoy & $\begin{array}{l}\text { DSA } \\
\text { Synmmetrical narrowing of distal ICA, proximal MCA and ACA } \\
\text { Hazy basal collateral vessels } \\
\text { MRI } \\
\text { Signal voids in the basal ganglia } \\
\text { rete Mirabile (sing of extensive collateral vessels in enhanced } \\
\text { MRI) }\end{array}$ & $\begin{array}{l}\text { TCD } \\
\text { In stage } 2 \text { (moderate stenosis) } \\
\text { Increased MFV and decreased PI } \\
\text { In stage } 3 \text { (severe stenosis) } \\
\text { Decreased MFV and increased PI } \\
\text { Low MFV (<40 cm/sec) had more stroke or } \\
\text { neurological deterioration }\end{array}$ \\
\hline Sickle cell disease & Stenosis or occlusion of the distal ICA and/or proximal MCA & $\begin{array}{l}\text { Elevated peak systolic velocity require further } \\
\text { monitoring or transfusion }\end{array}$ \\
\hline
\end{tabular}

CT; computed tomography, MRI; magnetic resonance image, DSA; digital subtraction angiography, HR; high-resolution, TCD; transcranial Doppler, CA; internal carotid artery, MCA; middle cerebral artery, ACA; anterior cerebral atery, MFV; mean flow velocity, PI; pulsatility index.

diagnose or predict the prognosis of uncommon causes of stroke (cervical artery dissection [CAD], Takayasu arteritis [TA], PFO-stroke, MMD, and SCD).

\section{CAD}

CAD is caused by laceration of the cervical artery, usually from the inner wall, and is characterized as a hematoma within the arterial wall. ${ }^{1,2}$ Initially, an intimal tear occurs, which allows the blood to enter the media under arterial pressure. Separation of the wall layers causes a false lumen where blood leaks into the vessel wall, forming the hematoma. This results in a stenosis of the lumen, potentially leading to occlusion or an aneurysmal dilatation of the artery. Furthermore, the damage to the endothelium affects exposure of the thrombogenic subendothelium; it may cause platelet aggregation and subsequent ischemic stroke. ${ }^{3}$ The most common symptoms of internal carotid artery (ICA) dissection include headache and neck pain, occurring in $80 \%$ of patients. ${ }^{1}$ Other frequent signs include partial Horner's syndrome, painful tinnitus, and ipsilateral lower cranial nerve palsies. ${ }^{4}$ Because nerve fibers for 
sweating in the face travel along the external carotid artery, the Horner's syndrome is usually partial without anhidrosis. ${ }^{5}$ In vertebral artery (VA) dissection, headache and severe neck pain, mostly in the occipitocervical area, are the most common clinical features. In intracranial VA dissection, subarachnoid hemorrhage occurs in over $50 \%$ of cases. ${ }^{6}$

CAD can be classified on the basis of pathogenesis (traumatic vs. spontaneous) and location (extracranial vs. intracranial). Traumatic dissections are due to direct trauma or rapid head movement. In spontaneous dissections, extracranial segments of ICA and VA are much more likely to undergo dissection than their intracranial segments. Extracranial ICA dissection affects the cervical part of the artery distal to the carotid bulb and tends not to extend beyond its entry into the petrous portion. Because of the abrupt turn of the VA at the first-to-second cervical vertebrae, most VA dissections happen at the level of the first and second vertebrae. Intracranial dissections more commonly affect posterior circulation than anterior circulation.?

Although dissections are often preceded by direct major trauma to the neck, development of dissection is likely multifactorial, affected by both genetic predisposition and minor trauma. Other risk factors include migraine headaches, pregnancy and postpartum, previous infection, connective tissue disease, and hypertension. ${ }^{1,2}$ Despite the suspected role of minor trauma, it is not typical for minor traumas, such as whiplash or sudden head movements, to cause dissection in most patients. Therefore, it is hypothesized that patients who sustain a dissection with or without minor trauma likely have an underlying arteriopathy, inflammatory process, or structural instability of the arteries that leads to dissection.

\section{Conventional imaging}

Conventional computed tomography angiography (CTA), magnetic resonance angiography (MRA), and digital subtraction angiography (DSA) primarily show the lumen of the dissected artery. CTA has shown promising results in visualization of vessel stenosis or occlusion and vessel diameter extension, as well as associated vessel tortuosities. ${ }^{8,9}$ The most common finding in CTA is an irregular and asymmetrical vessel, followed by intramural hematoma, which appears as a crescentic hyperdensity with thickening of the vessel wall. CTA can also detect intimal flaps and dissecting aneurysms (Fig. 1A). CTA shows better spatial resolution for severely narrowed vessels. Thus, some reports suggest that CTA is superior to MRA for the diagnosis of pseudoaneurysm, intimal flaps, and high-grade stenosis. ${ }^{10}$ However, CTA may be less accurate if heavy calcifications are present. Studies comparing imaging modalities for the diagnosis of VA dissections versus ICA dissections reported that CTA may be slightly preferential for VA dissections because of smaller diameters of the VA and their close proximity to the bony structures in the neck. ${ }^{8}$

MRA has replaced DSA as the gold standard, at least in the extracranial segments of ICA and VA. Advantages of MRA include better evaluation of intramural hematomas, regardless of the luminal irregularities. Usually, hematoma presents as a hyperintense area beside the vessel lumen. However, because it may be isointense early on, it may be difficult for magnetic resonance imaging (MRI) to detect the hematoma in the early stages of dissection.

Subtle luminal irregularities and small aneurysmal dilatations could be missed with MRA, as compared with DSA (Fig. 2A). The characteristic MRA findings in extracranial CAD include a decrease or absence of sig-
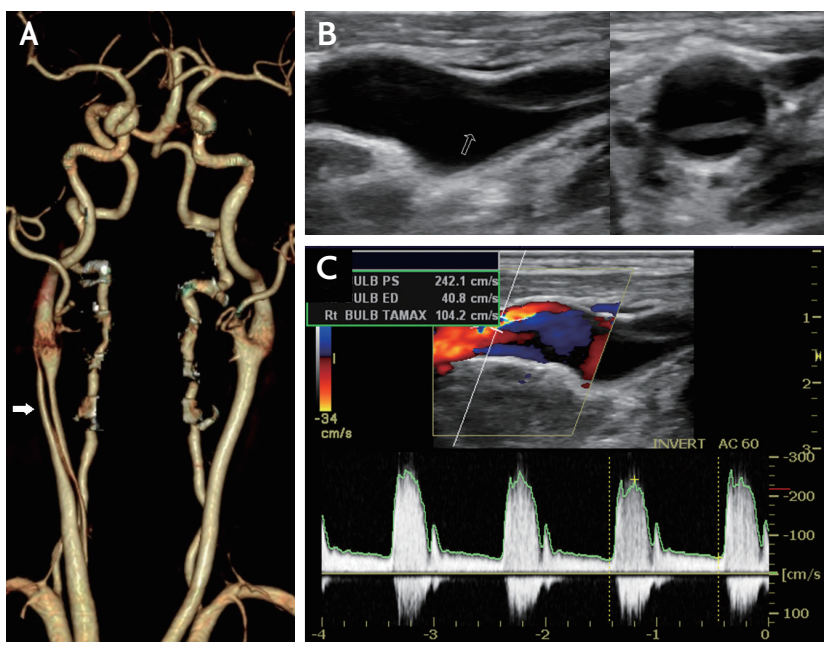

FIG. 1. Common carotid artery dissection. (A) Computed tomography angiography shows arterial dissection and intimal tear (arrow). (B) Ultrasound shows intimal flap (arrow) without evidence of atherosclerosis. (C) Ultrasound with color Doppler demonstrates high resistance flow profile with mixed flow direction. 
nal void and a crescent sign resulting from narrowing of the vessel by intramural dissection with a periarterial rim of intramural hematoma in T1-weighted images (Fig. 2B). ${ }^{9}$ These findings are quite specific and can be seen in ICA, VA, and basilar artery dissection. However, for the smaller intracranial vessels, the diagnostic role of MRI remains limited, and the diagnosis of these dissections still remains a challenge. ${ }^{9}$ In such cases, high-resolution MRI (HR-MRI) can be useful. (see below). ${ }^{11}$

DSA has long been recognized as the standard technique for diagnosing $\mathrm{CAD}$. The most common finding with DSA is string sign, which is a long segment of narrowed lumen. The artery may show sudden tapering with a distal occlusion of the lumen. In some cases, aneurysmal dilatations can be found in the initial or follow-up imaging studies (Fig. 2C). However, DSA cannot directly visualize vessel wall abnormalities or detect intramural hematomas. Furthermore, pathognomonic features of dissection, such as an intimal flap or a double lumen, are found in less than $10 \%$ of cases. ${ }^{12}$ Thus, DSA may miss the diagnosis if the lumen is only minimally affected. Therefore, less invasive imaging modalities such as ultrasound, MRI/MRA, and CTA have been alternatively used instead of DSA in the majority of CAD.

\section{Neurosonologic evaluation and vessel wall imaging}

Color duplex imaging is a simple, widely available, and noninvasive technique. It can also be used for follow-up monitoring of dissection, as it is less invasive. Signs of dissection on ultrasound include direct visualization of an intimal flap or intramural hematoma as a thickened hypoechoic wall (Fig. 1B). Arterial stenosis or occlusion without atherosclerotic wall change also can be seen. Thus, Doppler spectra may demonstrate a high-resistance pattern (Fig. 1 C) ${ }^{13}$ In addition, the findings that can be observed in transcranial Doppler include reversed ophthalmic artery flow or other intracranial collaterals and microemboli found in the middle cerebral artery (MCA) unilateral to a suspected carotid lesion. The main limitations of ultrasound include inability to visualize dissections above the angle of the mandible and difficulty in identifying the VA dissection.

HR-MRI for vessel wall imaging usually can be used to assess various vascular pathologies other than atherosclerosis, even in the intracranial vessels. When assessing intracranial artery disease, HR-MRI is one of the most important imaging techniques for directly evaluating the vascular wall. Intracranial artery atherosclerosis, dissection, MMD, vasculitis, and reversible cerebral vasoconstriction syndrome can be
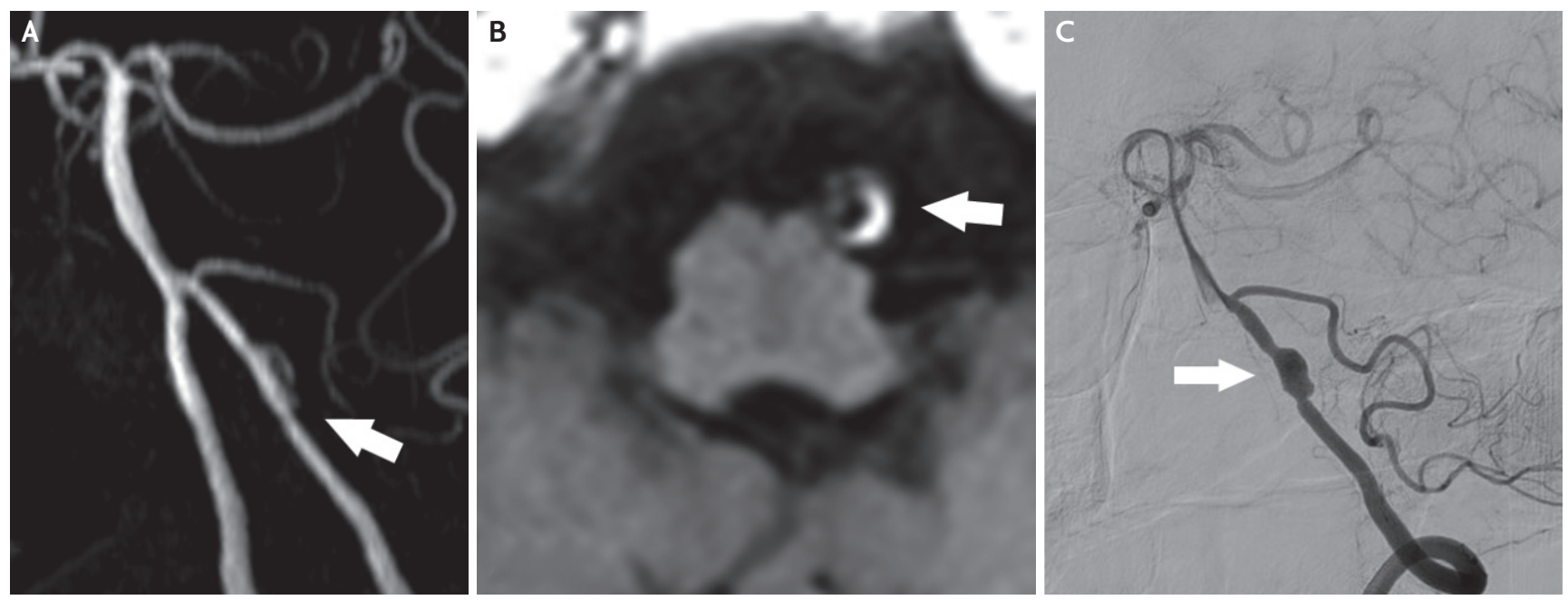

Fig. 2. Left distal vertebral artery dissection. (A) Time-of-flight MRA shows luminal irregularity and aneurysmal dilatation (arrow). (B) Axial T1-weighted MRI demonstrates dark circle of flow void surrounded by a bright hyperintense crescent shaped intramural hematoma (arrow). (C) Digital subtraction angiography demonstrates dissecting aneurysm (arrow). MRA; magnetic resonance angiography, MRI; magnetic resonance imaging. 
diagnosed and differentiated using HR-MRI. ${ }^{14}$ This technique can offer excellent visualization of both the arterial wall and lumen, thus enabling the detection of various features of CAD. The typical features of CAD include intimal flap, double lumen, eccentric wall thickening, vessel wall enhancement, and intramural hematoma. ${ }^{15}$ Although vessel wall enhancement is not completely understood, it has been thought to result from inflammation, slow blood flow in the false lumen, or enhancement of the vasa vasorum. ${ }^{16}$ The lumen of the vessel and intimal flap are well visualized on $\mathrm{T} 2$ and proton density sequences, whereas hyperintense intramural hematoma in the arterial wall is well visualized on $\mathrm{T} 1$ and magnetization-prepared rapid acquisition gradient-echo sequences due to the presence of methemoglobin. ${ }^{15}$ Also, HR-MRI could help to clearly differentiate intramural hematoma from intraluminal thrombus. ${ }^{11}$ The clinical benefits of HR-MRI include providing detailed information of vascular structures, such as an ostium of a small branching vessel or the presence of an intramural hematoma on the aneurysmal wall. It can help to determine treatment strategies, such as intervention. Because arterial dissection may be a dynamic vascular pathology, HR-MRI findings can change over time, and serial changes may have to be estimated to make a diagnosis and predict the prognosis. $^{17}$

\section{TA}

TA is another rare cause of stroke involving the extracranial arteries. TA is a form of panarteritis of medium and large sized arteries, namely the aorta and its main branches. ${ }^{18}$ Pathologically, granulomatous inflammation with massive intimal fibrosis of the aorta and its major branches leads to wall thickening and thrombus formation. ${ }^{19}$ TA mostly presents in the 2 nd or 3 rd decade of life but varies among different populations. ${ }^{18}$ There have been many case reports and clinical studies since it was first diagnosed. The left subclavian artery is the most commonly affected site, followed by the descending thoracic aorta, aortic arch, and ascending aorta. ${ }^{20}$ Common symptoms are claudication, headaches, dizziness, syncope, visual changes, and carotidynia. TA patients present reno-vascular hypertension, bruits at the carotid area, absent pulses, and asymmetric blood pressure between extremities. ${ }^{21}$ Usually TA is incidentally diagnosed, often with a delay in diagnosis from the onset of the first symptoms.

Angiography remains the gold standard for diagnosis of TA. To classify the disease on the basis of angiographic findings, a new classification of TA has been proposed. These systems are useful in that they allow a comparison of patient characteristics according to the vessels. ${ }^{18}$ TA diagnostic criteria were initially amended by the American College of Rheumatology in 1990 and modified in 1995, resulting in a higher sensitivity for diagnosis. ${ }^{22}$ The diagnostic criteria are shown in Table 2.

\section{Conventional imaging}

Angiography has been regarded as necessary for the diagnosis of TA. Three imaging techniques (CTA, MRA, and DSA) are commonly used.

CTA is useful for early diagnosis and can be used to evaluate both the vessel walls and the lumen. However, it has limitations in patients with renal failure and pregnancy, and it cannot detect relatively small vessels. $^{23}$

During the acute stage, MRA can show wall thickening and enhancement around an inflamed vessel. During the chronic stage, there is segmental dilatation with stenotic regions of the common carotid and subclavian arteries. In advanced-stage disease, CTA and MRA may reveal complete occlusion of supra-aortic arteries at their origin, with multiple bypass collateral vessels. 23,24

DSA is the most accurate diagnostic method. Involvement of the aorta or of at least two medium-sized branches is essential for diagnosis. DSA has better resolution than CTA and MRA for the detection of changes in small arteries. However, it is invasive and direct evaluation of the vessel walls is not possible. ${ }^{23}$

\section{Neurosonologic evaluation}

Doppler ultrasound is a useful non-invasive procedure for the assessment of wall inflammation. Carotid ultrasonography may reveal the typical features of arterial inflammation, concentric wall thickening and evidence of the homogeneously isoechoic (brighter than 
TABLE 2. Modified diagnostic criteria for Takayasu arteritis (1995)

\begin{tabular}{|c|c|}
\hline Criteria & Definition \\
\hline \multicolumn{2}{|l|}{ Three major criteria } \\
\hline Left mid subclavian artery & $\begin{array}{l}\text { Severe stenosis or occlusion from the point } 1 \mathrm{~cm} \text { proximal to the vertebral artery } \\
\text { orifice to that } 3 \mathrm{~cm} \text { distal to the orifice }\end{array}$ \\
\hline Right mid subclavian artery & $\begin{array}{l}\text { Severe stenosis or occlusion from the point } 1 \mathrm{~cm} \text { proximal to the right vertebral ar- } \\
\text { tery orifice to that } 3 \mathrm{~cm} \text { distal to the orifice }\end{array}$ \\
\hline $\begin{array}{l}\text { Characteristic signs and symptoms of at least } \\
\text { one month duration }\end{array}$ & $\begin{array}{l}\text { Limb claudication, pulseless or pulse difference in limbs, unobtainable or significant } \\
\text { blood presence difference (>10 } \mathrm{mmHg} \text { systolic blood pressure difference in limb), } \\
\text { fever, neck pain, transient amaurosis, blurred vision, syncope, dyspnea or palpita- } \\
\text { tion }\end{array}$ \\
\hline \multicolumn{2}{|l|}{ Ten minor criteria } \\
\hline High ESR & ESR $>20 \mathrm{~mm} / \mathrm{h}$ (Westergren) \\
\hline Carotid artery tenderness & Unilateral or bilateral tenderness of common carotid artery \\
\hline Hypertension & $\begin{array}{l}\text { Persistent blood pressure }>140 / 90 \mathrm{mmHg} \text { at brachial artery or }>160 / 90 \mathrm{mmHg} \text { pop- } \\
\text { liteal }\end{array}$ \\
\hline Aortic regurgitation or annuloaortic ectasia & $\begin{array}{l}\text { By auscultation or Doppler echocardiography or angiography } \\
\text { By angiography or two-dimensional echocardiography }\end{array}$ \\
\hline Pulmonary artery lesion & $\begin{array}{l}\text { Lobar or segmental arterial occlusion by angiography or perfusion scintigraphy, } \\
\text { presence of stenosis, aneurysm, luminal irregularity in pulmonary trunk or pulmo- } \\
\text { nary arteries }\end{array}$ \\
\hline Left mid common carotid lesion & $\begin{array}{l}\text { Stenosis or occlusion in the mid portion of } 5 \mathrm{~cm} \text { in length from the point } 2 \mathrm{~cm} \text { distal } \\
\text { to its orifice }\end{array}$ \\
\hline Distal brachiocephalic trunk lesion & Stenosis or occlusion in the distal third lesion \\
\hline Descending thoracic aorta lesion & $\begin{array}{l}\text { Narrowing, dilation or aneurysm, luminal irregularity or any combination deter- } \\
\text { mined by angiography: tortuosity alone is unacceptable }\end{array}$ \\
\hline Abdominal aorta lesion & Narrowing, dilatation or aneurysm, luminal irregularity by angiography \\
\hline Coronary artery lesion & $\begin{array}{l}\text { Documented on angiography below the age of } 30 \text { years in the absence of risk fac- } \\
\text { tors like hyperlipidemia or diabetes mellitus }\end{array}$ \\
\hline
\end{tabular}

Presence of two major or one major and two minor criteria or four minor criteria suggests a high probability of Takayasu arteritis.

that of temporal arteritis) "macaroni sign" (Fig. 3). The macaroni sign is an early sign of TA, even if arterial stenosis has not yet occurred. The neurosonologic assessment of TA should include examination of the carotid arteries, subclavian arteries, and common femoral arteries. ${ }^{25} \mathrm{~B}$-mode ultrasound can often help in identifying typical anatomic features of TA. Furthermore, contrast-enhanced ultrasound may allow the identification of inflammation-driven hyperemia and neovascularization, which are potential markers of disease activity. ${ }^{26}$ Therefore, although the gold standard for diagnosis is brain MRA or CTA, ultrasound has been also been highly sensitive in diagnosing TA.

Transcranial Doppler (TCD) is useful in evaluating blood flow velocity and direction of the large intra- cranial arteries around the circle of Willis. It allows noninvasive assessment of cerebral hemodynamic alterations that occur as a consequence of extracranial large vessel stenosis in TA. ${ }^{27}$ The salient TCD findings in TA include "pulseless" cerebral vascular spectra ipsilateral to the extracranial lesion and reorganization of collateral flow consequent to arterial stenosis and occlusion. ${ }^{28}$ Hemodynamic changes include abnormal spectral flow patterns and flow velocities indicative of steno-occlusive disease, changes in pulsatility, microembolic signals (MES), and reorganization of collateral circulation. ${ }^{28}$ In these cases, TCD provides a valuable, dynamic, noninvasive, and longitudinal evaluation of cerebral perfusion.

TCD can also be used for detection of subclavian 

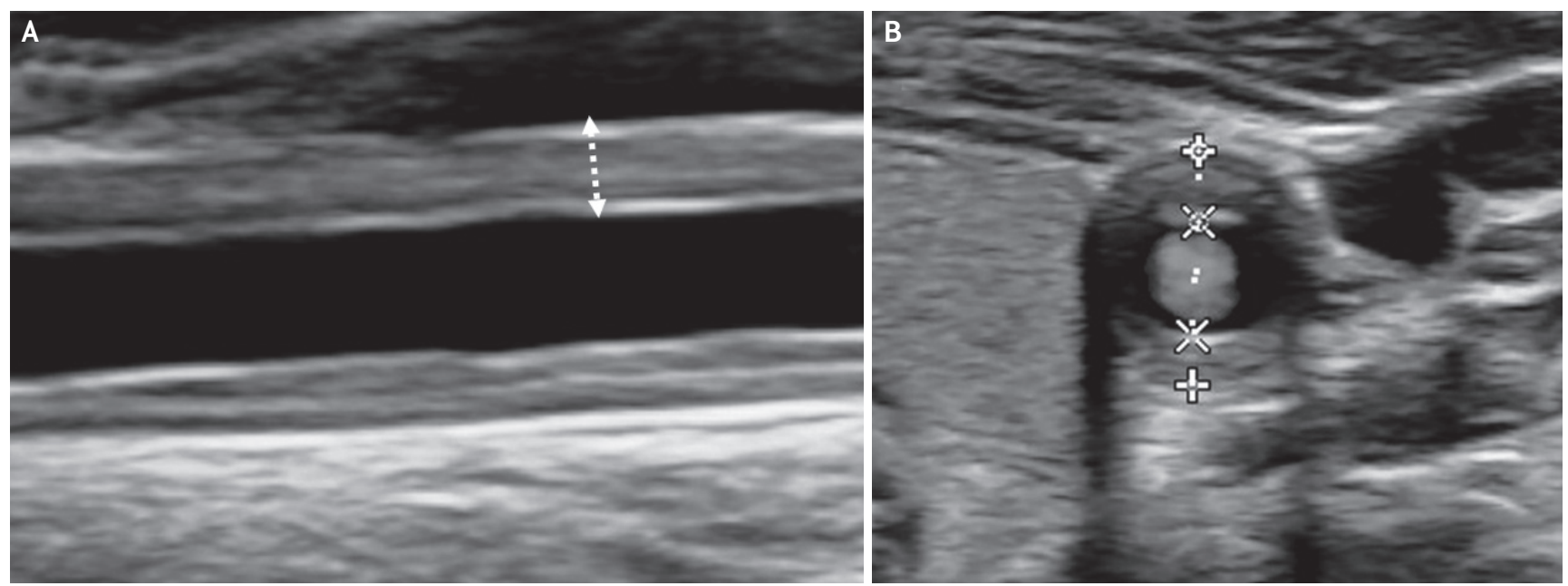

FIG. 3. Takayasu arteritis. Longitudinal (A) and transverse (B) scan of ultrasound shows the "macaroni sign" (homogeneous, iso-echoic, and concentric wall thickening) at the common carotid artery.

steal syndrome in patients with subclavian artery occlusion. ${ }^{27}$ Disease progression is the key factor in determining whether to treat or not. Clinical presentation and current laboratory markers, such as erythrocyte sedimentation rate, are not consistently reliable markers of disease activity because clinically inactive patients have shown histologically active disease. ${ }^{29}$ Therefore, quantitative study by neurosonologic follow-up and monitoring of clinical manifestations in TA patients with carotid involvement is a safe, sensitive, and efficient means of detecting the presence of progression or plateau in the course of TA. ${ }^{29}$

\section{PFO-STROKE}

PFO is one of the most common developmental anomalies of the heart. PFO is found in one-fourth of the general population. However the incidence of $\mathrm{PFO}$ is increased to $60 \%$ in stroke patients with unknown cause. ${ }^{30}$ PFO may cause ischemic stroke by paradoxical embolism. Thrombus formed from the venous system may shunt from the left to the right atrium, resulting systemic embolization..$^{\circ}$

\section{Conventional imaging}

Thrombi in the right atrium must pass the PFO to be embolized to the brain. Therefore, the thrombi are small in size, and the ischemic lesion caused by paradoxical embolism is usually small. At same time, there are fewer angiographic occlusions observed in cerebral arteries. As PFO-stroke is mainly embolic, the lesions are usually located at the cortex. ${ }^{31}$ The Valsalva maneuver increases blood flow to posterior circulation, while simultaneously increasing the amount of right-to-left shunt. Therefore, several studies have reported that posterior circulation infarction is more dominant in PFO-stroke. ${ }^{31,32}$ This is more prominent when the PFO is only opened during the Valsalva maneuver. ${ }^{33}$

Not all strokes occurring in those who have PFO, are associated with PFO. Half of the PFO in stroke patients are innocent bystanders. Identifying which PFO is truly associated with stroke is important regarding the treatment strategy. Young patients without other risk factors may have a higher association between PFO and stroke. Risk of paradoxical embolism (RoPE) score is a scoring system widely used to predict the association between PFO and stroke. ${ }^{34}$

\section{Neurosonologic evaluation}

Transesophageal echocardiography is the gold standard in identifying the presence of $\mathrm{PFO}$, especially high risk PFO. A size of more than $2 \mathrm{~mm}$ and those with atrial septal aneurysm are regarded as high risk PFO. ${ }^{35}$ However, it is difficult to perform the Valsalva maneuver effectively due to the transducer placement 
in the esophagus. Therefore, a TCD-PFO test may have a supplementary role in detecting right-to-left shunt. A mixture of saline with air $(9 \mathrm{~mL}$ and $1 \mathrm{~mL}$, respectively; agitated saline) is injected to the antecubital vein and the Valsalva maneuver is maintained for approximately 10 seconds. If MES appear in the TCD within $15 \mathrm{sec}-$ onds after injection, the patient is considered to have an intra-cardiac right-to-left shunt, mostly PFO. On the other hand, if MES are observed 15 seconds after injection and last for a longer time, there is the possibility of extra-cardiac shunt, such as a pulmonary arteriovenous fistula. MES are more readily observed from the right temporal window than the left, and in the case of a poor temporal window, MES can be measured at the posterior circulation.

\section{MMD}

MMD is a cerebrovascular disease primarily involving the distal ICA and proximal MCA in a symmetric manner, with progressive stenosis and growth of abnormal small vessels (Moyamoya vessels). ${ }^{36}$ The progressive stenosis causes hemodynamic insufficiency, resulting in cerebral ischemia. Furthermore, the abnormally developed Moyamoya vessels are weak and prone to hemorrhage, leading to intracerebral and intraventricular hemorrhage. ${ }^{36}$ The prevalence is high in east Asian countries and shows mild predominance in females (male:female, 1:1.8). It also shows an age-related bimodal distribution and is predominant in young adolescents and the middle-aged.

The major pathologic findings are smooth muscle cell proliferation, intimal thickening, and angiogenesis. ${ }^{37}$ Recent studies with HR-MRI showed that the stenosis progresses with constrictive remodeling. ${ }^{38,39}$ Family histories and several genetic loci were found in $10-15 \%$ of MMD patients; one locus is the ring finger 213 (RNF 213) gene, which was shown to be a susceptible gene for MMD in Asians. However, the exact pathophysiologic role of RNF 213 requires further research. Several other studies also focused on inflammation and autoimmune disease in the mechanism of MMD. ${ }^{40}$ One-in-five MMD patients show disease progression; the presence of thyroid disease and mutation in RNF 213 gene are known factors with a high probability of progression. The incidence of stroke is $3.2-4.5 \%$, and known risk factors are female gender, smoking, family history of MMD, thyroid disease, and posterior cerebral artery involvement. ${ }^{41,42}$

\section{Conventional imaging}

The gold standard for diagnosis of MMD is DSA, which is useful not only for diagnosis but for treatment decisions. "Definite MMD" can be diagnosed when the distal ICA, proximal MCA, and ACA are symmetrically involved and hazy basal collateral vessels are confirmed. If only one side is involved, "probable MMD" can be diagnosed. If there are other conditions which can cause stenosis, the term "Moyamoya syndrome" is used. There are 6 stages of disease progression, according to the angiographic findings (Table 3).

Brain MRI and MRA are also useful in evaluation of MMD. In MRI, signal voids are observed in the basal ganglia. In the enhanced MRI, "rete mirabile", a network of extensive collateral vessels can be shown. Involvement of distal ICA, proximal MCA, and ACA can also be confirmed by MRA. It is especially useful for young patients who need frequent follow-up, as it is noninvasive. However, because of low specificity, it is often difficult to differentiate MMD from other cerebrovascular diseases (Fig. 4).

\section{Neurosonologic evaluation}

TCD is also useful for screening and follow-up studies in MMD patients, as it is non-invasive. Both anatomical information and hemodynamic status can be evaluated; most of the ischemic stroke in MMD is hemodynamic. The TCD findings correlate well with the TCD flow velocity and pulsatility index (PI). In stage

TABLE 3. Suzuki grading for Moyamoya disease

\begin{tabular}{ll}
\hline Suzuki stage & \multicolumn{1}{c}{ Angiographic finding } \\
\hline I & Narrowing of carotid arteries \\
II & Initial appearance of moyamoya vessels \\
III & Intensification of moyamoya vessels \\
IV & Minimization of moyamoya vessels \\
V & Reduction of moyamoya vessels \\
VI & Disappearance of moyamoya vessels \\
\hline
\end{tabular}



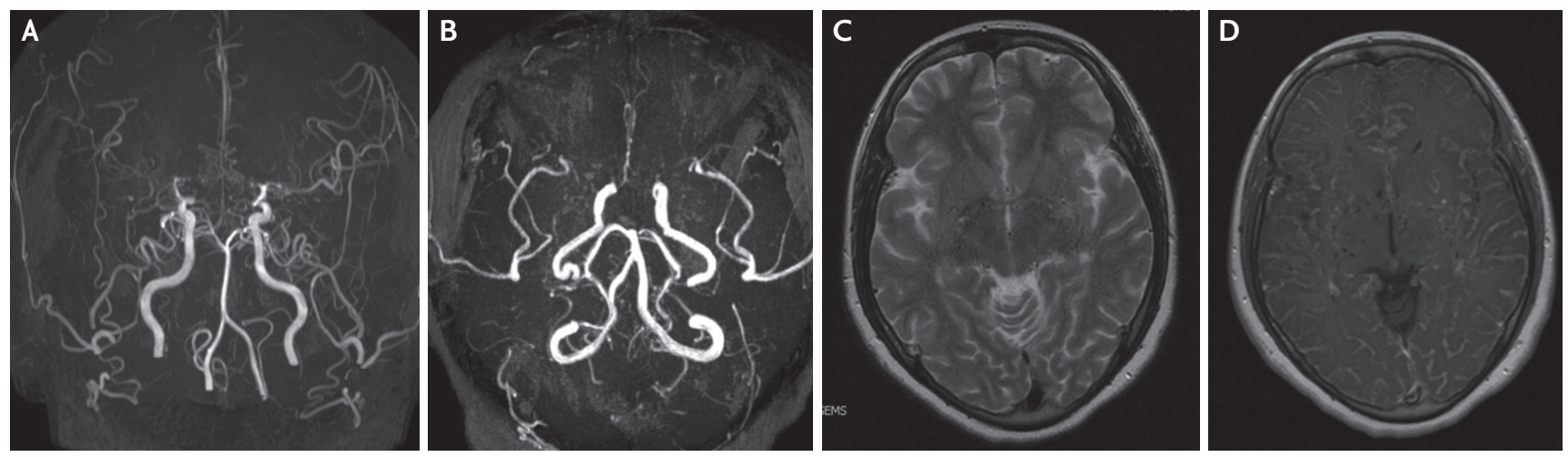

FIG. 4. Brain MRA and MRI findings of Moyamoya disease. (A) Brain MRA shows obliteration bilateral MCAs and ACA and more prominent Moyamoya vessel in advanced stage (Suzuki III). (B) Anterior circulation is rarely observed and Moyamoya vessel is also diminished in more advanced stage (Suzuki IV). (C) Multiple signal voids that reflect collateral vessel are revealed on bilateral basal ganglia in T2 weighed image. (D) T1-weighted image with gadolinium enhancement reveals prominent leptomeningeal enhancement, representing leptomeningeal collateral. MRA; magnetic resonance angiography, MRI; magnetic resonance imaging.

2 (moderate stenosis), the mean flow velocity (MFV) increases and PI decreases. In stage 3 (severe stenosis), the MFV decreases and PI increases. TCD is also useful in evaluating the collateral status. As a progressive disease, flow though the distal ICA decreases, leptomeningeal collateral increases from the anterior and posterior circulation, and transdural collateral from the external carotid artery increases. According to one study, in the lower Suzuki grades (o-2), the main collateral was from the leptomeningeal collateral, whereas in the advance stage (Suzuki grade >2), transdural collateral developed. ${ }^{43}$ The development of transdural collateral was inversely correlated with flow through the distal ICA, as measured by carotid Doppler sonography. Those with transdural collateral had smaller infarctions with less neurological deficit. ${ }^{43}$ TCD and duplex sonography are useful evaluating hemodynamics in MMD patients. TCD was also useful predicting stroke or neurological deterioration after bypass surgery. Patients with low MFV ( $<40 \mathrm{~cm} / \mathrm{sec}$ ) had more stroke or neurological deterioration after direct bypass surgery. ${ }^{44}$

\section{SCD}

SCD is an inherited autosomal disorder resulting from the formation of abnormal hemoglobin S, which is extremely rare in Korea. Cerebral infarction is a common complication of SCD and may manifest as overt stroke or cognitive impairment associated with "silent" cerebral infarction on MRI. These strokes primarily result from stenosis or occlusion of the distal intracranial ICA and/or proximal MCA. ${ }^{45}$ Stenotic lesions have been demonstrated by DSA, MRI, and TCD. However, DSA is invasive and not suitable for screening asymptomatic patients.

TCD can detect intracranial arterial stenosis and seems ideally suitable for screening large-vessel disease in patients with SCD because it is safe, noninvasive, relatively low in cost, and well tolerated by children..$^{45}$ A comparison of TCD with cerebral angiography in patients with SCD showed a sensitivity of $91 \%$ and a specificity of $100 \%$ in determining which patients had arterial narrowing that exceeded $50 \%$ of the luminal diameter. ${ }^{45}$ Specifically, peak systolic velocity, rather than time average maximum mean velocity, could be the measurement of choice for TCD screening with the highest sensitivity. Some previous studies demonstrated that increased velocity of flow, as assessed by TCD, can identify the patients at highest risk of stroke, suggesting that most cerebral infarctions in SCD are associated with large-artery disease. ${ }^{46}$ Blood transfusion therapy significantly reduces the risk of recurrent cerebral infarction and prevents the progression of lesions on angiography. ${ }^{47,48}$

\section{FUTURE DIRECTIONS}

Neuroimaging techniques have been developed to 
focus on the brain parenchyma. Recently, several efforts have been made to focus on the vessel wall. HR-MRI is now useful in evaluating the etiology and pathophysiology of vessel wall structure. However, conventional imaging techniques have some limitations regarding radiation, motion artifacts due to long scan times, and high price for frequent follow-up.

Neurosonology has advantages, as it is safe, uses no radiation, and can evaluate hemodynamics. Therefore, it is suitable for frequent follow-up. Furthermore, in cases of carotid ultrasonography, wall pathology can be easily confirmed. TCD and Doppler mode in carotid duplex sonography has advantages in evaluating and monitoring the hemodynamics of cerebral vessels. These advantages can be complementary to conventional imaging techniques.

\section{CONCLUSION}

As treatment strategy and prognosis may differ from that of common stroke etiologies, diagnosis of uncommon causes stroke is important. Neuroimaging and neurosonologic evaluation can be helpful for the diagnosis of uncommon causes stroke. In particular, imaging techniques that directly focus on vessel wall pathology (i.e., HR-MRI) and hemodynamic status (TCD or duplex sonography) can provide information that informs decisions on treatment strategy and prognosis after procedures in patients with uncommon causes of stroke.

\section{Acknowledgments}

We would like to thank Soyoen Choi for dedicated work in the neurosonologic evaluation of the stroke patients and for providing the carotid ultrasonography images.

This work was supported by the National Research Foundation of Korea (NRF) grant funded by the Korean government (MSIT) (No. 2017R1CiB5017843).

\section{Conflicts of Interest}

No potential conflicts of interest relevant to this article was reported.

\section{REFERENCES}

1. Debette S, Leys D. Cervical-artery dissections: predisposing factors, diagnosis, and outcome. Lancet Neurol. 2009;8:668678.

2. Kim YK, Schulman S. Cervical artery dissection: pathology, epidemiology and management. Thromb Res. 2009;123:810821.

3. Volker W, Dittrich R, Grewe S, Nassenstein I, Csiba L, Herczeg L, et al. The outer arterial wall layers are primarily affected in spontaneous cervical artery dissection. Neurology. 2011;76:1463-1471.

4. Lee VH, Brown RD Jr, Mandrekar JN, Mokri B. Incidence and outcome of cervical artery dissection: a population-based study. Neurology. 2006;67:1809-1812.

5. Sturzenegger M. Spontaneous internal carotid artery dissection: early diagnosis and management in 44 patients. $J$ Neurol. 1995;242:231-238.

6. Friedman AH, Drake CG. Subarachnoid hemorrhage from intracranial dissecting aneurysm. J Neurosurg. 1984;60:325334 .

7. Debette S, Compter A, Labeyrie MA, Uyttenboogaart M, Metso M, Majersik JJ, et al. Epidemiology, pathophysiology, diagnosis, and management of intracranial artery dissection. Lancet Neurol. 2015;14:640-654.

8. Provenzale JM, Sarikaya B. Comparison of test performance characteristics of MRI, MR angiography, and CT angiography in the diagnosis of carotid and vertebral artery dissection: a review of the medical literature. AJR Am J Roentgenol. 2009;193:1167-1174.

9. Provenzale JM. Dissection of the internal carotid and vertebral arteries: imaging features. AJR Am J Roentgenl. 1995;165:1099-1104.

10. Vertinsky AT, Schwartz NE, Fischbein NJ, Rosenberg J, Albers GW, Zaharchuk G. Comparison of multidetector CT angiography and MR imaging of cervical artery dissection. AJNR Am J Neuroradio. 2008;29:1753-1760.

11. Hunter MA, Santosh C, Teasdale E, Forbes KP. High-resolution double inversion recovery black-blood imaging of cervical artery dissection using 3'T MR imaging. AJNR Am J Neuroradiol. 2012;33:E133-E137.

12. Houser OW, Mokri B, Sundt TM Jr, Baker HL Jr, Reese DF. Spontaneous cervical cephalic arterial dissection and its residuum: angiographic spectrum. AJNR Am J Neuroradiol. 1984;5:27-34.

13. Hennerici M, Steinke W, Rautenberg W. High-resistance 
Doppler flow pattern in extracranial carotid dissection. Arch Neurol. 1989;46:670-672.

14. Oppenheim C, Naggara O, Touzé E, Lacour JC, Schmitte E, Bonneville F, et al. High-resolution MR imaging of the cervical arterial wall: what the radiologist needs to know. Radiographics. 2009;29:1413-1431.

15. Swartz RH, Bhuta SS, Farb RI, Agid R, Willinsky RA, Terbrugge KG, et al. Intracranial arterial wall imaging using high-resolution 3-tesla contrast-enhanced MRI. Neurology. 2009;72:627-634.

16. Sakurai K, Miura T, Sagisaka T, Hattori M, Matsukawa N, Mase M, et al. Evaluation of luminal and vessel wall abnormalities in subacute and other stages of intracranial vertebrobasilar artery dissections using the volume isotropic turbo-spin-echo acquisition (VISTA) sequence: a preliminary study. J Neuroradiol. 2013;40:19-28.

17. Choi YJ, Jung SC, Lee DH. Vessel wall imaging of the intracranial and cervical carotid arteries. J Stroke. 2015;17:238-255.

18. Johnston SL, Lock RJ, Gompels MM. Takayasu arteritis: a review. J Clin Pathol. 2002;55:481-486.

19. Vaideeswar P, Deshpande JR. Pathology of Takayasu arteritis: a brief review. Ann Pediatr Cardiol. 2013;6:52-58.

20. Li J, Sun F, Chen Z, Yang Y, Zhao J, Li M, et al. The clinical characteristics of Chinese Takayasu's arteritis patients: a retrospective study of 411 patients over 24 years. Arthritis Res Ther. 2017;19:107.

21. Lai KL, Chen HH, Lan JL, Chen DY. Ultrasonography of large-vessel vasculitides. Journal of Medical Ultrasound. 2012;20:72-78.

22. Sharma BK, Jain S, Suri S, Numano F. Diagnostic criteria for Takayasu arteritis. Int J Cardiol. 1996;54 Suppl:S141-S147.

23. Abdel Razek AA, Alvarez H, Bagg S, Refaat S, Castillo M. Imaging spectrum of CNS vasculitis. Radiographics. 2014;34:873894.

24. Gyftopoulos A, Despotopoulos E, Kiriakopoulos N, Delimpasis G. Takayasu arteritis :the role of MRI and MR angiography. Aunnal Scientific Meeting; 2013 Oct 24-26; London, United Kingdom. Vienna: European Society of Cardiac Radiology; 2013.

25. Cantú C, Pineda C, Barinagarrementeria F, Salgado P, Gurza A, Paola de Pablo, et al. Noninvasice cerebrovascular assessment of Takayasu arteritis. Stroke. 2000;31:2197-2202.

26. Magnoni M, Dagna L, Coli S, Cianflone D, Sabbadini MG, Maseri A. Assessment of Takayasu arteritis activity by carotid contrast-enhanced ultrasound. Circ Cardiovasc Imaging. 2011;4:e1-e2.
27. Suwanwela NC, Suwanwela N. Takayasu arteritis: ultrasonographic evaluation of the cervico-cerebral arteries. Int $\mathrm{J}$ Cardiol. 1998;66 Suppl 1:S163-S173.

28. Christiansen ME, O'Carroll CB, Kumar G, Larsen BT, Dumitrascu OM. Transcranial Doppler evaluation in Takayasu arteritis with oculo-cerebrovascular complications. Neurologist. 2019;24:17-21.

29. Sun Y, Yip PK, Jeng JS, Hwang BS, Lin WH. Ultrasonographic study and long-term follow-up of Takayasu's arteritis. Stroke. 1996;27:2178-2182.

30. Bang OY, Lee MJ, Ryoo S, Kim SJ, Kim JW. Patent foramen ovale and stroke-current status. J Stroke. 2015;17:229-237.

31. Kim BJ, Sohn H, Sun BJ, Song JK, Kang DW, Kim JS, et al. Imaging characteristics of ischemic strokes related to patent foramen ovale. Stroke. 2013;44:3350-3356.

32. Boutet C, Rouffiange-Leclair L, Garnier P, Quenet S, Delsart D, Varvat J, et al. Brain magnetic resonance imaging findings in cryptogenic stroke patients under 60 years with patent foramen ovale. Eur J Radiol. 2014;83:824-828.

33. Hayashida K, Fukuchi K, Inubushi M, Fukushima K, Imakita S, Kimura K. Embolic distribution through patent foramen ovale demonstrated by (99m)Tc-MAA brain SPECT after Valsalva radionuclide venography. J Nucl Med. 2001;42:859-863.

34. Kent DM, Ruthazer R, Weimar C, Mas JL, Serena J, Homma $\mathrm{S}$, et al. An index to identify stroke-related vs incidental patent foramen ovale in cryptogenic stroke. Neurology. 2013;81:619-625.

35. Lee JY, Song JK, Song JM, Kang DH, Yun SC, Kang DW, et al. Association between anatomic features of atrial septal abnormalities obtained by omni-plane transesophageal echocardiography and stroke recurrence in cryptogenic stroke patients with patent foramen ovale. Am J Cardiol. 2010;106:129-134.

36. Suzuki J, Takaku A. Cerebrovascular "moyamoya" disease. Disease showing abnormal net-like vessels in base of brain. Arch Neurol. 1969;20:288-299.

37. Takagi Y, Kikuta K, Nozaki K, Hashimoto N. Histological features of middle cerebral arteries from patients treated for Moyamoya disease. Neurol Med Chir (Tokyo). 2007;47:1-4.

38. Kim YJ, Lee DH, Kwon JY, Kang DW, Suh DC, Kim JS, et al. High resolution MRI difference between moyamoya disease and intracranial atherosclerosis. Eur J Neurol. 2013;20:1311-1318.

39. Ryoo S, Cha J, Kim SJ, Choi JW, Ki CS, Kim KH, et al. High-resolution magnetic resonance wall imaging findings 
of Moyamoya disease. Stroke. 2014;45:2457-246o.

40. Yamada H, Deguchi K, Tanigawara T, Takenaka K, Nishimura Y, Shinoda J, et al. The relationship between moyamoya disease and bacterial infection. Clin Neurol Neurosurg. 1997;99 Suppl 2:S221-S224.

41. Cho WS, Chung YS, Kim JE, Jeon JP, Son YJ, Bang JS, et al. The natural clinical course of hemodynamically stable adult moyamoya disease. J Neurosurg. 2015;122:82-89.

42. Noh HJ, Kim SJ, Kim JS, Hong SC, Kim KH, Jun P, et al. Long term outcome and predictors of ischemic stroke recurrence in adult moyamoya disease. J Neurol Sci. 2015;359:381388.

43. Hong JM, Hong YH, Lee SJ, Lee SE, Lee JS, Shin DH. Hemodynamic contribution of transdural collateral flow in adult patients with moyamoya disease. Neurol Sci. 2016;37:1969-1977.

44. Cho H, Jo KI, Yu J, Yeon JY, Hong SC, Kim JS. Low flow ve- locity in the middle cerebral artery predicting infarction after bypass surgery in adult moyamoya disease. J Neurosurg. 2017;126:1573-1577.

45. Adams R, McKie V, Nichols F, Carl E, Zhang DL, Mckie K, et al. The use of transcranial ultrasonography to predict stroke in sickle cell disease. N Engl J Med. 1992;326:605-610.

46. Naffaa LN, Tandon YK, Irani N. Transcranial Doppler screening in sickle cell disease: the implications of using peak systolic criteria. World J Radiol. 2015;7:52-56.

47. DeBaun MR, Gordon M, McKinstry RC, Noetzel MJ, White DA, Sarnaik SA, et al. Controlled trial of transfusions for silent cerebral infarcts in sickle cell anemia. N Engl J Med. 2014;371:699-710.

48. Adams RJ, McKie VC, Hsu L, Files B, Vichinsky E, Pegelow C, et al. Prevention of a first stroke by transfusions in children with sickle cell anemia and abnormal results on transcranial Doppler ultrasonography. N Engl J Med. 1998;339:5-11. 